\title{
دراسة نظرية في الذحو و الإعراب
}

\section{Sriwahyuningsih R Saleh}

E-Mail: sriwahyuningsih@umgo.ac.id

\section{Sastra Arab, Fakultas Ilmu Budaya - UM Go}

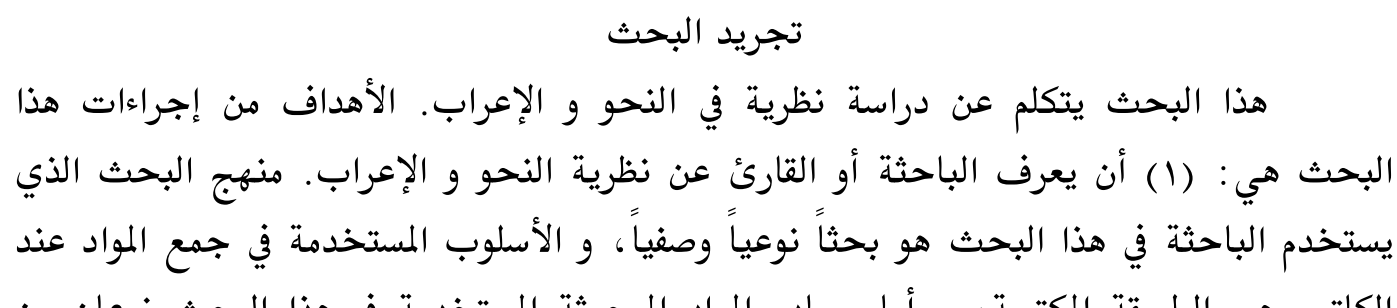

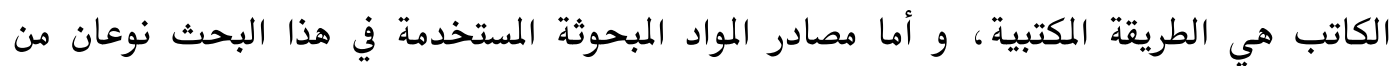

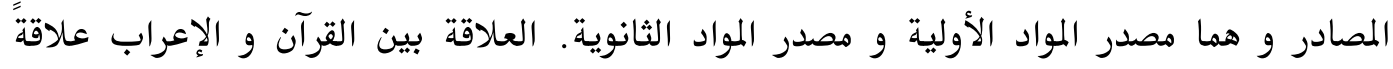

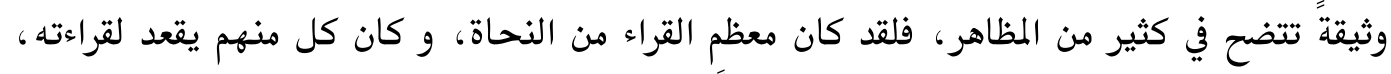

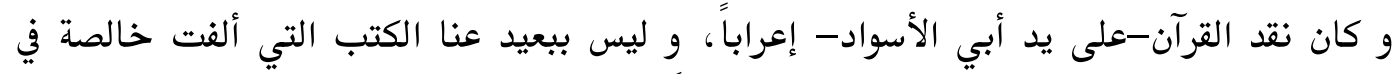

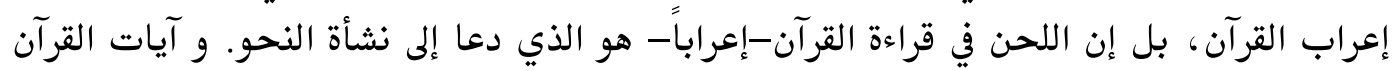

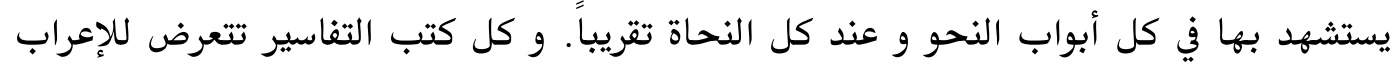

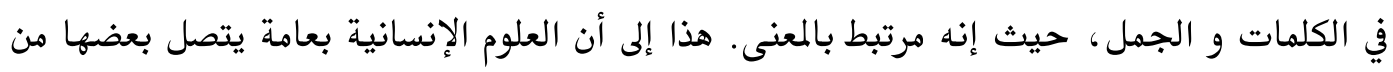

الإعراب بكسر الهمزة مصدر من الفعل أَعَرَبَ يُعِب إعرَاباً، وهو بمعنى البيان والإيضاح

والإفصاح. قال الأزهري: الإعراب و التعريب معناهما واحد، وهو الإبانة .يقال :أعرب عنه لسانُه و عرَّب أي أبان وأفصح ·ويقال :أعرب عما في ضميرك أي أبن .ومن هذا يقال للرجل إذا أفصح في

\section{'A Jami Jurnal Bahasa dan Sastra Arab}

Volume 08, No. 1, Juni 2019 ISSN: 2252-9926 (Print), ISSN: 2657-2206 (Online) 
الكلام :قد أَعرب ا"و في الأجرمية : الإعراب هو تغيير أواخر الكلم، لاختلاف العوامل الداخلة عليها لفظاً أو تقديراً. و أقسامه أربعة : رفع، و نصب، و خفض، و جزم.r الإعراب في اللغة : مصدر قياسي من قولك : أعربت إعراباً . والمراد به : الإظهار والإبانة فنقول " أعربت عمّا في نفسي" أي أظهرته وأبنته .وفي الحديث الشريف : "الثيب يُعرب عنها لسانها والبكر تستأمر و في نفسها" والمراد : يظهره ويبين عنها لسانها. كذلك ورد في القاموس المحيط : الإعراب الإبانة و الإفصاح عن شيء....و الإعراب أن لا يلحن في الكلام.ب والإعراب في اصطلاح النحاة هو تغيير يلحق آخر الكلمة حقيقة أو حكماً بسبب اختلاف العوامل الداخلة عليها من عامل يقتضي الرفع إلى آخر يقتضي النصب إلى ثالث يقتضي الجر إلى رابع يقتضي الجزمء. فنقول أن الإعراب هو تغير أواخر الحركة أو الحروف في الكلمة سبب اختلاف العوامل الدالخلة عليها إما أن تكون لفظاً أو تقديراً. استعمل الذحاة كلمة (الإعراب) في ثلاثة معان اصطلاحية ، وهي: ا. ما يرادف الذحو r. تحليل الكلام نحويا ب. ما يقابل البناء. قال : نحا الشىء يذحاه و يذحوه إذا حرفه، و منه سمي النحوي لأنه يحرف الكلام إلى وجوه الإعراب، و نَحوُ العربية إنما هو انتحاء سمت كلام العرب في تصرُفه من اعراب و غيره، كالتثنية و الجمع و التحقير و التكبير و الإضافة و النسب.ه و قال: هو علم يعرف أحوال أواخر الكلام إعراباً و بناءً. علم النحو هو علم يعرف به كيفية التركيب العربي صحة وسقما، وكيفية ما يتعلق بالألفاظ من حيث وقوعها فيه. والغرض منه الاحتراز عن الخطأ في التأليف والاقتدار على فهمه والإفهام به.

$$
\text { ا ابن مذظور، لسان العرب(، بيروت : دار صادر) طا ، صيده }
$$

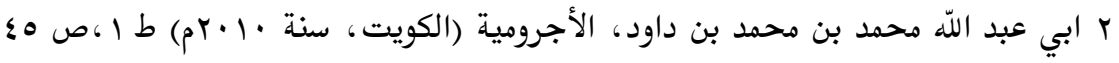

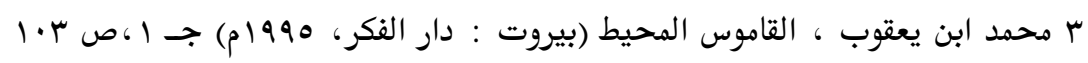

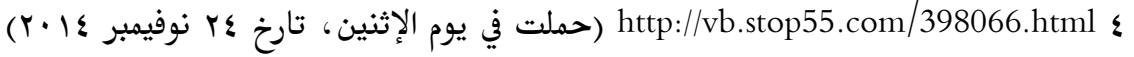

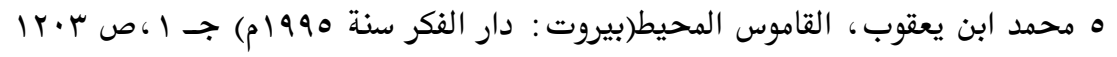

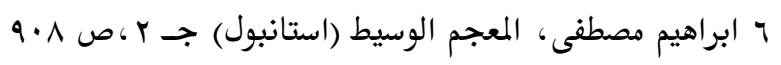

\section{'A Jami Jurnal Bahasa dan Sastra Arab}

Volume 08, No. 1, Juni 2019 ISSN: 2252-9926 (Print), ISSN: 2657-2206 (Online) 
تعريف النحو لغة، الذحو : الطريق و الجهة و هو مشتق من الفعل نحا و الجمع أنحاءو نُحُوُ، و نحوت الشىئُ قصدته فالنحو : القصد، و منه نحو العربية، و هو إعراب الكلام العربي، لأن المتكلم ينحو به منهاج كلام العرب إفرادا و تركيباً، و النحوي العالم بالنحو، و الجمع نحويون و نحاة.

قال ابن جني أن النحو هو انتحاء سمت كلام العرب، في تصريفه من إعراب و غيره، كالتثنية و الجمع، و التحقير و التكسير و الإضافة، و النسب، و التركيب، و غير ذلك، ليلحق من ليس من أهل اللغة العربية بأهلها في الفصاحة، فينطق بها و إن لم يكن منهم، و إن شد بعضهم عنها رد به إليهاV . و الحقيقة أن ابن جني قد سبق علماء عصره بهذا النص و جاء بما تعارف عليه اللغويون المحدثون، فقد جمع في هذا النص بين لونين من الدراسات : صرفية و تنضح في التثنية و الجمع و التحقير (التصغير)...، و نحوية : تنضح في الإضافة و الإعراب و التركيب. و هذان النوعان من الدراسة و هما الصرف (Morphology) و التركيب (Synaxe) يكونان في الدراسات اللغوية الحديثة ما يسمى بعلم النحو (Grammar). و لتفصيل ذلك أقول : إن الدراسات اللغوية الحديثة تجمع بين علم النظم و علم التراكيب(Synaxe) ، و علم الصيغ الصرفي(Morphology) تحت باب واحد و هو باب النحو $: \wedge($ Grammar $)$ ا ـ فأما علم النظم أو التراكيب (Synaxe) فهو يعني أول كل شيئ بترتيب الكلمات في

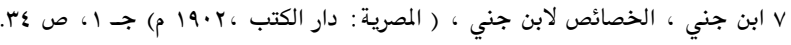

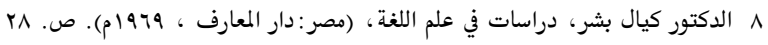

\section{'A Jami Jurnal Bahasa dan Sastra Arab}

Volume 08, No. 1, Juni 2019 ISSN: 2252-9926 (Print), ISSN: 2657-2206 (Online) 
4

جمل أي أنه يدرس الطرق التي تتألف بها الجمل من الكلماته. و يهتم هذا العلم أيضاً بأشياء أخرى لا تقل أهمية عن تركيب الكلمات و تأليفها في الجمل، من هذه الأشياء البحث في قوانين المطابقة (Concord) أو عدم المطابقة من حيث العدد (الإفراد و التثنية و الجمع) من حيث النوع (التأنيث و التذكير) مثلاً. و من وظيفة علم التراكيب كذلك البحث في الإعراب و قوائنه • 1. r. الشق الثاني من علم النحو و هو علم الصيغ (Morphology) و هو ما يعرف في الأوســــــاط اللغوية بعامة بعلم الصرف، و يقوم بدراسات الوحدات الصرفية و الصيغ اللغوية || التي يتركب منها الكلام أو الجمل. فهذا الشق الثاني (الوحدات الصرفية و الصيغ اللغوية) أساس الشق الأول - علم التراكيب- و مكوناته. و تؤكد الدراسات اللغوية الحديثة أن علم التراكيب هو أشبه ما يكون ببناء كبير، مادته الوحدات الصرفية أو تسمى الموريغيمات 1 أ.

و من هذين الفرعين معاً تنتج الفصائل الذحوية ( Grammatical Catagories) كفصيلة العدد: المفرد و المثنى و الجمع، و فصيلة الجنس : المذكر و المؤنث، و فصيلة التعريف و التنكير: النكرة و أنواع المعارف و هي الضمير و العلم و أسماء الإشارة و الموصولة و المعرفة بال، و فصيلة الزمن : كماضي الفعل المضارعه و ظرف الزمان، و فصيلة الاشتقاق : كاسم الفاعل و المفعول و اسم الزمان و المكان و اسم الآلة و أفعل التفضيل و اسم المرة و اسم الهيئة و الصفة المشبهة و الصيغة المبالغة، و فصيلة التوابع كالصة و العطف و البدل و التوكيد، و فصيلة النعاني الوظفية: كالفاعلية و المفعولية و الاضافة و الاستثناء و التمييز.

$$
\begin{aligned}
& 9 \text { (الدكتور كيال بشر، دراسات في علم اللغة، صه؟r. }
\end{aligned}
$$

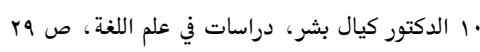

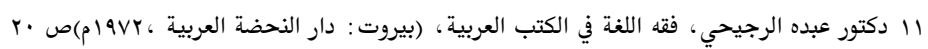

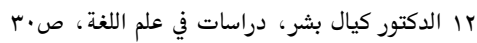

\section{'A Jami Jurnal Bahasa dan Sastra Arab}

Volume 08, No. 1, Juni 2019 ISSN: 2252-9926 (Print), ISSN: 2657-2206 (Online) 
النحو نوعان: بَصْريٌ، وكُوفِيٌ، والبَصْريٌّ أسبق وجودًا من الكُوفِيِ، وإليه يُرَدُّ

وَضْع النحو، ما في ذلك خلاف ولا مِراء، فمن حقِه علينا أن نبدأ به، والحديث عنه ذو

شِقِّنْن : الأوَّل عن بيئة النحو، والآخر عن واضعه.

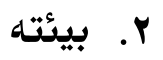

نَشَاً النحوُ في البَصْرَةٍة، وما كان له أن ينشأ في غيرها؛ فهي المدينة التي اشتدَّتْ

فيها الحاجة إليه قبل غيرها، إذ لم تكد تُمَصَّرُ، ويتسامع الناس بها وبوَفْرة الخيرات

فيها ، حنّى انثالتُ إليها أفواج من العرب، وأخرى منَ العجم.

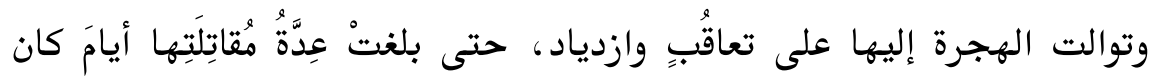

زياد واليًا عليها - ثمانين أَلْفا، وبلغت عِدَّة عيالهم مائة وعشرين ألفاًا اه ، وكان تمصيرها

سنة § 1، وولاية زياد سنةَ هـ فكلٌّ ما بينهما نحو ثلاثين عامًا.

وعاش أهل البصرة منَ العرب والعجم كما يعيش أهل الوطن الواحد من أصول

مختلفة، تجمعهم أواصرِهُ، وتدعوهم دواعي العيش فيه إلى التفاهُم والمعاملة، ولا يمكن أن يتمَّ تفاهُمُ، وتتيسر معاملة إلا باللغة، فلم يكن بدُّ لهذه الأخلاط منَ اصطناع لغةٍ واحدة، إلى جانب لُغاتها المتعدِّدة؛ فكانت العربية هي هذه اللغة؛ لأنّها لُغة الدولة القائمة،

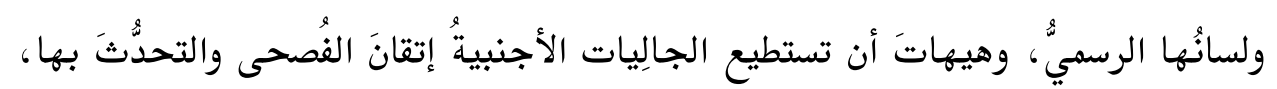

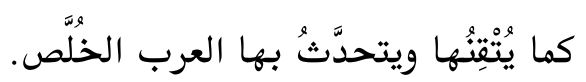

لذلك أصبحت العربيَّة عَرَيَّتَيْن : فصيحة يصطعنها العرب، وأخرى يَشوبها قليل أو كثير منَ اللَّحْنْ والتحريف، يتحدَّث بها المُستعربُون في الحياة العامَّة، على أنَّ اللَّحْن

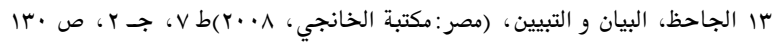

\section{'A Jami Jurnal Bahasa dan Sastra Arab}

Volume 08, No. 1, Juni 2019 ISSN: 2252-9926 (Print), ISSN: 2657-2206 (Online) 
6

والتحريف كانا يشُوبان لُفةَ العرب أو بعضِهم أيضًا، ولكن بمقدار، وعلى تغاوت واختلاف.

فقد رَووْا أنَّ عمر - رضي الله عنه - جاءه كتاب من عامله على مِيسَانَ، وقد

$$
\text { لَحَنَ كاتبه فيه، ف فكتب عمر إلى العامل : أن قَنّعْ كاتبك سَوْطَّ ا. . }
$$

وشيُوٌ آخَرُ يُوَيِّدُ ظهور النحو في البصرة، وهو: أنّ الإمام عَلِيَّا، وعبداللّه بن

عبَّاس، وأبا الأسود الدؤليَّ - كانوا يقيمون بالبصرة، سَبَقَ إليها أبو الأسود، وجاءها الإمام وابن عباس أيامَ الفتنة الكبرى، ويتنازع الرواة نِسبة وَضْع الذحو إلى ثلاثتهم في كثير من الروايات، ومعقولٌ أن يكون وَضْع الذحو إبَّانَ هذه الحقبة : إذ كان خِلاطُ العرب والعجم حينئذ أَشَدَّ، واللحنُ في العربية أكثرَ، والحاجةٌ إلى الذحو آكََ.

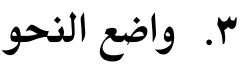

وردت رواياتُ شتَّى عن واضع النحو، تتحدَّث عنه من جوانبه المختلفة، تتحدَّث

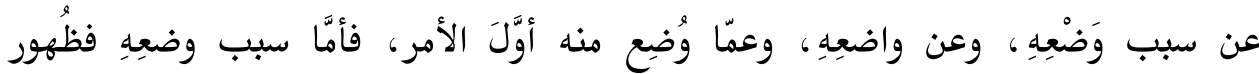

$$
\text { اللَّحْنْ، واستفحال خَطَرِه على مَرِّ الأيام. }
$$

وكانت العرب تَمْقُت اللَّحْنَ أشدَّ المَقْتِ، وتراه مَنْقَصَةً تُزْري بصاحِبها، لا في

مطلع الإسلام فحسنْبُ؛ ولكن فيما تلاه كذلك إلى أَمَدٍ بعيد، وكانوا لا يَسكتون عن لَحْنَةٍ

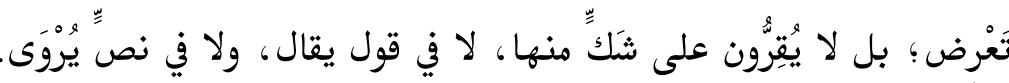

وقد وردت رواياتُ كثيرةٌ تعزو وَضْع النحو إلى أبي الأسود، بلا خلاف بينها ، إلا

في سبب وضعِه والمُضيّ فيه : أكان إحساسًا بضرورته ، أم كان إثارةً من عُمَرَ، أم من الإمام

$$
\text { عليٍِّ أم أم من زياد؟ }
$$

ع الجاحظ ، البيان و التبيين، ط V، جـ ص ص rV

Www.alukah.net/literature 10

\section{'A Jami Jurnal Bahasa dan Sastra Arab}

Volume 08, No. 1, Juni 2019 ISSN: 2252-9926 (Print), ISSN: 2657-2206 (Online) 
ويبدو أنَّ الأمر شُبِّة على القائلين بإشارة عمر، وإشارة زياد، فحَسِبَ الأولون أنَّ عَهْدَ عمر إلى أبي الأسود في تعليم الإعراب - يعني إثارةً بوضع النحو، وحَسِبَ الآخرون

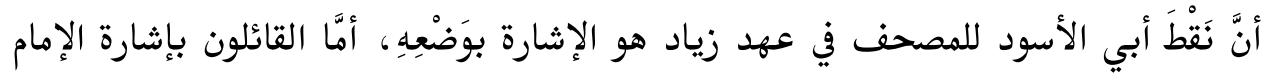

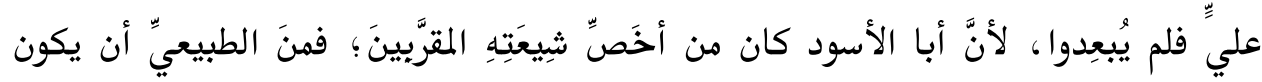
على صلةٍ ما بنحو أبي الأسود، إشارةً به أو إرشادًا فيه.

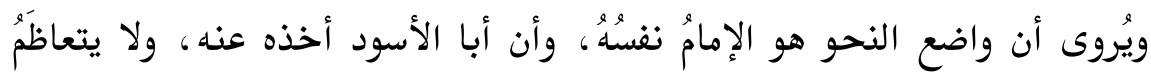

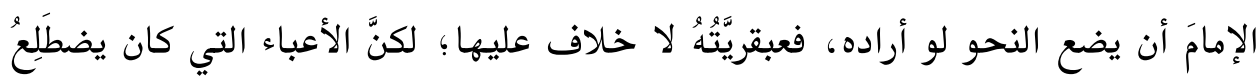

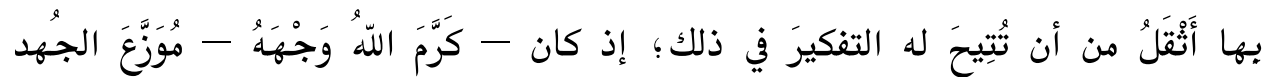
والفِكر لتَتُبيتِ دعائم الدولة، وإقامَّة أحكام الدين، وتدبير شؤون الرَّعِيَّة، وإحباط

وفي أخبار أبي الأسود شواهدُ تدل على أنَّهَ كان - كما توسَّم فيه عُمَر - صاحبَ

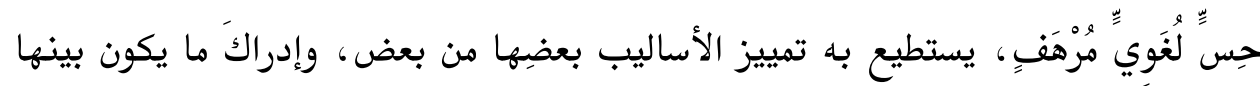
من أوجُهِ الخِلاف والمشابهة، وما يكون لذلك من أثثر في المعنى صحة وفسادًا.

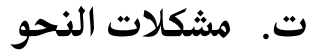

هناك مشكلات كثيرة تَحُول بين دراسة النحو وبين إتقانه، منها ما هو متعلق بالضَّف العام في اللغة العربية في المجتمع العربي؛ بسبب اختلاف اللغة المنطوقة في حياة الناس العادية عن اللغة المكتوبة، واعتيادهم على اللغة المنطوقة، فيَنشأ "اللحن" في اللغة حين يريدون التحدث أو الكتابة بالعربية الفصيحة، ومنها ضَعف مُدرِّي اللغة العربية،

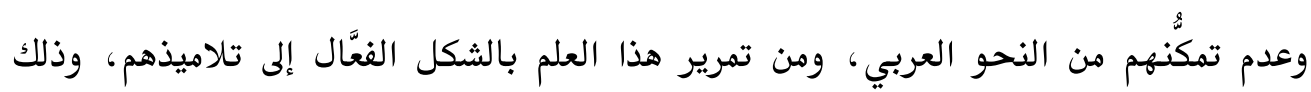
يَنتج أحيانًا من ممارسة وظيفة معلم اللغة العربية بهدف طلب الرزق، أكثر مما هو إرادة ومحبَّة في رفُع مستوى هذه اللغة في واقع المجتمع العربي. Www.alukah.net/literature 17

\section{'A Jami Jurnal Bahasa dan Sastra Arab}

Volume 08, No. 1, Juni 2019 ISSN: 2252-9926 (Print), ISSN: 2657-2206 (Online) 
8

ونحن سنركِّ على مشكلة رئيسية، نعتقد أنه إن تمَّت معالجتها بالشكل المطلوب،

فسوف تظهر نتائجُ طيّبة على مستوى إتقان النحو العربي نُطقًا وكتابة عند الطلاب، وسوف

نتتبَّع "جذور" تلك المشكلة تاريخيَّا؛ كي نحاول تقديم العلاج المناسب لها - إن شاء الله. المشكلة الرئيسية تكمُن في طريقة تدريس النحو العربي في المدارس، والتي تركّز

أساسًا على إتقان الإعراب، واستظهار القواعد النحوية وحفظها غيبًا، وفي العودة إلى جذور

المشكلة نجد أنفسنا أمام كمٍٍ من الصعوبات المتعلقة بمادة الذحو؛ من حيث هي إرث وصَلنا

منذ القِدم.

"وتتمثَّل مظاهر تلك الصعوبة في الجوانب التالية IV :

1. اعتماد النحاة في وضْعهم لعلم النحو على منطق العقل (المعيارية)، دون الاهتمام

بمنطق اللغة وطبيعتها (الوصفية)، وقد برَز ذلك في طريقة التناول والتعبير في كثير من

كتب النحو والصرف والبلاغة، ويُستثنى منها كتب قلة ظهَرت في أول عهد العرب

بهذه الدراسات؛ حيث قامت على الوصف في كثير من أبوابها، ولم تقع في المعيارية

إلا من قبيل التوسُع في التعبير؛ أمثال: كتاب سيبويه "الكتاب"، وكتابي عبدالقاهر

الجرجاني "أسرار البلاغة" و"دلائل الإعجاز"، وبعد أن انتهى عصر الاستشهاد،

استمرَّ اللغويون في دراسة اللغة عن طريق ما وضَعه السلف من قواعد اللغة، لا عن

مادة اللغة، من هنا بدأ فرضض القواعد على الأمثلة، وبدَأ القول بالوجوب والإيجاز.

أدَّى كل ذلك إلى ظهور كثير من الحدود والقيود والافتراضات، التي تتنافى

أحيانًا مع الواقع اللغوي؛ لذا فإن الاتجاه الحديث في تدريس اللغة، يقوم أولاً على

الوصف؛ وصف اللغة المستعملة للتلاميذ، وهذا ما تدعو إليه كثير من المؤتمرات

$$
\text { والندوات والدراسات العلمية في ذلك المجال. }
$$

WwW.alukah.net/literature IV

\section{'A Jami Jurnal Bahasa dan Sastra Arab}

Volume 08, No. 1, Juni 2019 ISSN: 2252-9926 (Print), ISSN: 2657-2206 (Online) 
r. تأنُّر واضعي علم الذحو بعلماء الكلام في أن كلَّ أثرِ لا بدَّ له من مؤنّر، والإمعان في ذلك إمعانًا انتهى إلى نظرية العامل، وإلى الحديث عن العِلل وعِلل العِلل. r. كثرة ما في القواعد من أقوال ومماحكات، واختلاف مسائلها، واعتمادها على التحليل المنطقي، الذي يستدعي حصْ الفكر لاستنباط الأحكام العامة من أمثلة كثيرة متنوعة؛ مما دعا علماء التربية أن ينادوا بتأخير دراسة القواعد إلى سنِّ المراهقة. ـ. جفاف النحو وصعوبته ، وتأكيده على مماحكات عقلية مجرَّدة بعيدة عن واقع الحياة العملية التي يعيشها التلاميذ، وهمُه التدقيق في الجمل والتراكيب اللغوية. ه. كثرة العوامل النحُوية، وتشعُب التفاصيل التي تَندرج تحت هذه القواعد، وتُزاحمها بصورة لا تُساعد على تثبيت المفاهيم في أذهان التلاميذ، بل إلى تشتيتها ونسيانها؛ وذلك لتجرُّها وبُعدها عن واقع الحياة التي يَحياها التلاميذ".

$$
\begin{aligned}
& \text { الفصل الثاني : حقائق الإعراب } \\
& \text { أ. تعريف الإعراب }
\end{aligned}
$$

جاء في اللسانه| عدة معان لكلمة الإعراب، منها : 1. فالإعراب بمعنى الإيضاح أو الإفصاح و منه قول - صلى الله عليه و سلم- (الثيب تعرب عن نفسها- أي تفصح) و يقال : أعرب عما في ضميرك أي أبن. r. أعرب الرجل: تزوج امرأة عروباً أو عربة و هي المرأة الضاحكة المتحببة إلى زوجها العاشقة له، المظهرة له ذلك، و بذلك فسّر قوله تعالى (عرباً أتراباً (سورة الواقعة آية rV (rV). و قيل للتوفيق بين المعنين : أولاً و الثاني إن المعرب للكلام كأنه يتحبب إلى السامع بإعرابه كما تتودد المرأة العروب إلى زوجها91 ـ ـ و عندي أن المعنى الثاني 
10

يتصل بالأول من حيث إن المرأة عندما تظهر لزوجها حبها و إخلاصها إنما تعرب -

$$
\text { أي توضح و تفصح- عن ذلك. }
$$

r. و من هذا المادة عند ابن جني ·r (عروبة) و العروبة (نكرة و معرفة) و ليوم الجمعة، و ذلك أن يوم الجمعة أظهر أمراً من بقية أيام الأسبوع، كما فيه من التأهب لها و التوجه إليها، و قوة الإشعار بها. قال الشاعر :

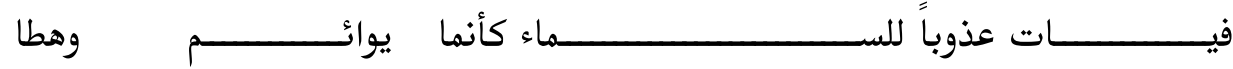

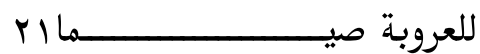

ع. ثم يتطور المعنى الثانى و هو إظهار التودد و العشق من المرأة لزوجها إلى الفحش من

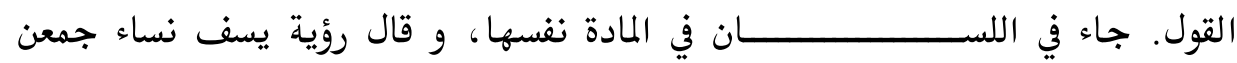
العفاف عند غرباء، و الإعراب عند الأزواج، و هو ما يستقحش من ألفاظ النكاح و

$$
\begin{aligned}
& \text { الجماع فقاله : } \\
& \text { و العُرُبْ في عفافةِ و إعرابِ }
\end{aligned}
$$

و واضح أن هذا الفحش مما يعد فساداً أو سلوكاً غير قويم، و على ذلك يكون قد جاء منه

(عَرَبَتْ معدة الفصيل) أي : فسدت. و عَرِبَ الجرح عرباً أي تقيح و فسد. و لابن الأنباري تعليل آخر لهذا المعنى، و هو الفساد، يقول: فإن قيل : العرب في قولهم (عَرَبَتْ معدة الفصيل) معناه الفساد، فكيف يكون الإعراب مأخوذاً منه؟ قيل : معنى قولك أعربت الكلام، أي أزلتَ عربَه و

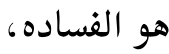

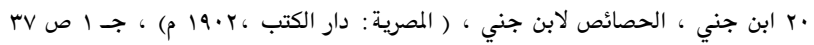

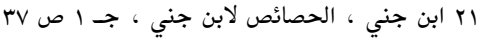

\section{'A Jami Jurnal Bahasa dan Sastra Arab}

Volume 08, No. 1, Juni 2019 ISSN: 2252-9926 (Print), ISSN: 2657-2206 (Online) 
11

ه. التعريب اتخاذ فرس عربي، كما أن التعريب في اللغة اتخاذ المنهج العربي (و منه عربة الفرس تعربا إذا بزغته ، و ذلك أن تذسف أسفل حافره، و معناه أنه قد بان بذلك ما كان خفيا من أمره لظهوره إلى مرأة العين بعد أن كان مستوراً) هذه كلها معان لغوية. و أما المعنى الاصتلاحي ، يعرفه الأستاذ عباس حسن بأنه (تغير العلامة التي في آخر اللفظ، بسبب تغير العوامل الداخلية عليه، و ما يقتضيه كل عامل)بr و في الشذور (الإعراب أثر ظاهر أو مقدر يجعله العامل في آخر الاسم الـمتمكن و الفعل

الـمتضارع)

و في حاشية الصيان على الأشموني (الإعراب في الاصطلاح مذهبان: الأول لفظي و اختاره النظم-يقصد ابن مالك-و نسبه إلى الـمحققين و عرفه في التسهيل بقوله : ما جيء به لبيان مقتضى العامل من حركة أو حرف أو سكون أو حذف. و مذهب الثاني معنوي

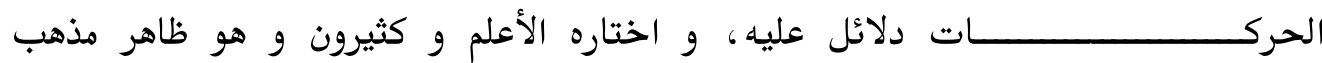

اختلف العلماء منذ القدم في نشأة اللغة، فمنهم من قال بأنها توفيقية، بمعنى أنها

منزلة من عند اللّه سبحانه و تعالى، و أن ليس للإنسان فضل في إيجادها، و آخرون قالوا إنها وضعية، أي من وضع الإنسان، صنعها لنفسه لتفي بمطالبه الأجتماعية. و أنبرى كل فريق المدفاع عن رأيه بتقديم الأدلة و البراهين و تبروا في ذلك، و تعددت الأبحاث في هذا المجال، حتى يحق لنا أن نقول إن هذا الموضوع قد قتل بحثا و تمحيصا، بل إن من العلماء من عد

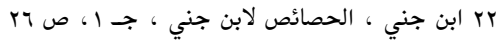

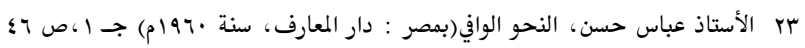

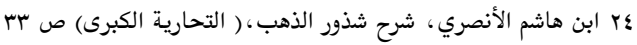

$$
\begin{aligned}
& \text { هب ابن مالك ،حاشية الصيان على شرح الألفية ابن مالك, (التجارية الكبرى) جـ 1 ،ص بـع }
\end{aligned}
$$

\section{'A Jami Jurnal Bahasa dan Sastra Arab}

Volume 08, No. 1, Juni 2019 ISSN: 2252-9926 (Print), ISSN: 2657-2206 (Online) 
12

البحث في نشأة اللغة أمرا من الأمور الميتافيزيقية، و أنه من المستحسن الانصراف عن مثل

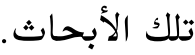

و ليس المجال هنا عرض آراء الفريقين و ترجيح واحد منهما، ولكنني أشرت إليها

لكي أنتقل إلى مسألة الإعراب، ذلك أنه إذا كان العلماء قد اختلفوا في نشأة اللغة، فإن نشأة الإعراب ربما تكون لها من الدلائل و البراهين ما يجعلنا نظن أنها اصتلاحية. و الدليل على ذلك أن اللغة عندما تعرب تكون قد وصلت إلى درجة الكمال، و يكون الإنسان الذي يتكلم بها قد وصل أيضاً إلى درجة الكمال العقلي و النمو الفكري، فكتابة لغة معربة أو النطق بلغة معربة يتطلب ذهناً واعياً و عقلاً نامياً ليطابق بين المعاني التى في نفسه و بين الرموز التى على أواخر الكلمات المنطوق بها، تلك الرموز التى تدل على ما يريد إظهاره من معاني. و لنفترض أن اللغة كانت في أول أمرها صيحات أو إشارات باليد أو مجرد أصوات تدل على الرغبات الشخصية للإنسان الأول... إلى آخر ما تقوله العلماء في هذا الصدد، ثم اكتسب الإنسان خبرة جعلته ينطق ببعض الأسماء لمسميات يعرفها و يشاهدها أمامه، ثم لمسميات يشعر بها و بعد ذلك وفق بين هذه الأسماء، فكانت الجمل. أليس معنى ذلك أن تكوين الجمل كان هو المرحلة الأخيرة في اللغة، و أنه كان نتيجة تطورات عديدة و خبرات مختلفة. فإذا كان الأمر كذلك فالإعراب ظاهرة تمثل قمة التطور اللغوي عند الإنسان، وليست مصاحبة لنشأة اللغة، ذلك لأن الإعراب لا يجيء إلا مع الجمل. على أنه لم يجيء دفعة واحدة. و مثله في ذلك مثل أي علم أو مجال حضاري آخر، فالرياضة مثلاً كانت في أول الأمر مجرد عمليات مبسطة في الجمع و الطرح و الضرب، ثم بارتقاء العقل و استمرار هذا الارتقاء قطعت الرياضة أشواطاً بعيدة حتى وصلت إلى النظريات الرياضية المعقدة التى انبنت عليها كثير من مظاهر المدنية الحديثة. كذلك فإن أحكام الإعراب تكونت بالتدريج تبعاً للرقي الاجتماعي و الحضاري للأمم.

\section{'A Jami Jurnal Bahasa dan Sastra Arab}

Volume 08, No. 1, Juni 2019 ISSN: 2252-9926 (Print), ISSN: 2657-2206 (Online) 
13

ثم كان من عمل الذحاة أن نقحوا هذه الأحكام و القواعد، وهذبوها و صنفوها في أبواب، و زادوا عليها، و أضافوا ما أضافوه من تأويلات و تعليلات و حذف و عوض. و لا يقول إن هذه علوم لغوية، و تلك علوم رياضية، فكلاهما صورة للحضارة الإنسانية بوجه عام، تلك الحضارة التى تخترعها و يهيمن علها العقل الإنساني، و التى تتناسب تناسباً طردياً مع رقي هذا العقل و تطوره. ننتقل الأن إلى الحديث عن تطور ظاهرة الإعراب في اللغة العربية بشيء من التفضيل، و نقول إن الشعر الجاهلي هو أقدم نص عربي معرب فصيح، حتى إذا أخذنا بنظرية المرحوم الأستاذ الدكتور طه حسين في أن معظم هذا الشعر منحول موضوع، فإنه سوف يتبقى لنا بعض

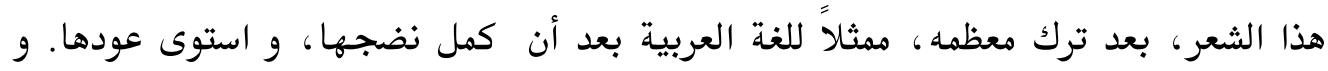

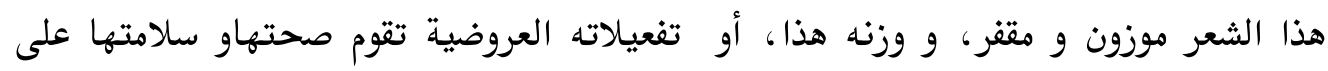
الإعراب من تنوين و حركة و سكون؛ إذ لا يمكن قراءة هذا الشعر دون كسر إذا أهملنا إعرابه. و بالطبع فإن هذه الصورة- صورة الشعر الجاهلي- لابد أن تسبقها صورٌ أخرى للغة ناقصة أو بدائية، و لابد أيضاً أن تكون تلك الصورة هي آخر حلقة في سلسلة التطورات اللغوية متضمنة الرقي الإعرابي. و الشعر الجاهلي كما يرجح معظم العلماء يرجع تاريخه إلى مائة و خمسين سنة أو مائتي سنة قبل البعثة المحمدية، يقول الجاحظ : ( أما الشعر فحديث الميلاد، صغير السن، أول من نهج سبيله و سهل الطريق إليه أمرؤ القيس بن حجر و هـلهل بن ربيعة... فإذا استظهرنا الشعر، وجدنا له- إلى أن جاء الله بالإسلام- خمسين و

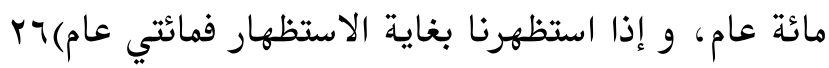
و إذن فلنرجع إلى الوراء ما أستطعنا حتى نتبين مظاهر الإعراب في اللغة التى سبقت

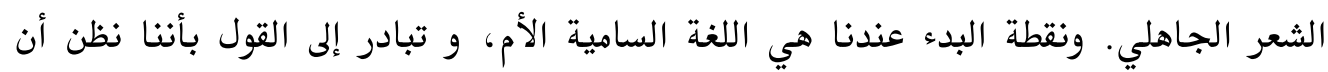
اللغة العربية هي اللغة السامية الأم نغسها، و ليس كما قال العلماء هي أقرب الساميات إلى بr ابن عثمان بن مجو الجاحظ الحيوان (بيروت: دار الكتب العلمية، 1970 م)ط Y، جـ ، ا ص ع V

\section{'A Jami Jurnal Bahasa dan Sastra Arab}

Volume 08, No. 1, Juni 2019 ISSN: 2252-9926 (Print), ISSN: 2657-2206 (Online) 
14

اللغة السامية الأم. و نظن أيضاً أن باقي الساميات هي لهجات أو لغيات ناقصة النمو متفرعة عن اللغة العربية، و الدليل على ذلك ما يلي : 1. أول هذه الأدلة و هو أهمها أننا إذا افترضنا أن اللغة العربية هي أقرب الساميات شبهاً باللغة السامية الأم، فأين اللغة السامية الأم إذن؟ يقولون إنها اندثرت و لا نملك منها نصوصاً مكتوبة و لا مروية في كتابات آخرينV. . و هذا شيء عجيب حقاً، فنحن لا نعرف هذه اللغة و لا نملك نصوصاً مكتوبة عنها، و لا نقوشاً، و لم يرو واحد من العلماء نصوصاً بهذه اللغة، ثم بعد ذلك نحكم بأنها كانت موجودة ثم اندثرت. كأننا نحكم على العدم بأنه كان موجوداً ثم أصبح عدماً. هذه واحدة و أخرى أن هذه اللغة السامية الأم إن كانت قد اندثرت، فلمَ لم تندثر اللاتينية أيضاً أو السنسكريتية و كلاهما لغة أم انثقت عنها لغات أخرى، بل كلاهما يقاربان اللغة السامية الأم في القدم؟ فاللاتينية يرجع تاريخ مرحلتها الأولى إلى سنة سه V ق.م عند إنشاء مدينة رومایى و السنسكريتية ترجع نصوصها الأدبية التى نعرفها إلى

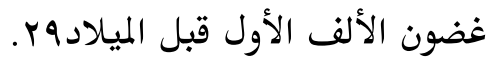
r. الإعراب الكامل في اللغة العربية: فإننا إذا اتبعنا منهج القارنة اللغوية اتضح لنا أن اللغات الأمهات (إذا جاز لنا هذا التعبير) كان تتميز بالإعراب، بالسنسكريتية، و اليونانية و اللاتينية-كما سبق أن أوضحنا- كان لغات معربة، من هذه اللغات الأمهات المعربة انبثقت لغات أخرى غير معربة. فمن اللاتينية تفرعت الفرنسية و البرتغالية و الألمانية... و من السنسكريتية تفرعت اللغة الفارنسية، و اللغات الهندية الحديثة، و من

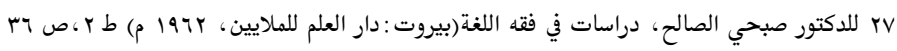

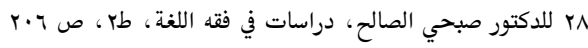

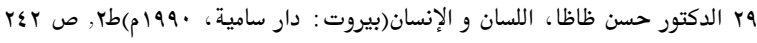

\section{'A Jami Jurnal Bahasa dan Sastra Arab}

Volume 08, No. 1, Juni 2019 ISSN: 2252-9926 (Print), ISSN: 2657-2206 (Online) 
15

اليونانية تفرعت اللغات اليونانية الحديثة.r. فما المانع أن تكون اللغة العربية هي الأصل الذي تفرع عنه باقي الساميات غير المعربات؟

r. يقرر العلماء أيضاً أن جميع ما تتميز به اللغة السامية الأم موجود في اللغة العربية و أن كل لغة سامية أخرى تحوى عنصراً أو عصرين أو عناصر من الخصائص العامة للغة السامية الأماس .أليس من الممكن تأدية هذا المعنى بألفاظ أخرى فنقول : إن العربية بها من الخصائص اللغوية ما ليس موجوداً في باقي الساميات، بينما أي خصيصة في لغة سامية أخرى موجودة في اللغة العربية، أي أن اللغة العربية جامعة لكل خصائص الساميات. فما المانع أن تكون هي الأم التي انبثق عنها باقي السساميات. ـ. يكاد يجمع العلماء على أن الموطن الأول للساميين كان القسم الجنوبي الغربي من شبه الجزيرة العربية (بلاد الحجاز و نجد و اليمن و ما إلى ذلك)بr و من هذا المهد تفرعت الهجرات السامية إلى العراق و الشام و ما جوارهما. و يأتي العلماء بالأدلة المقتعة بصدق

$$
\text { تـا هذا الرأيسمية الإعراب }
$$

لا يخفى على كل طالب علم ما لإعراب القرآن الكريم من فوائد تتجلى في ضبط الكلمات وفي معرفة معاني الآيات, لأن الإعراب يُميز المعانيءّ, قال الإمام مكي بن أبي طالب "أَعظمٌ ما يجب على الطالب لعلوم القرآن, الراغب في تجويد ألفاظه, وفهم معانيه, ومعرفة قراءاته ولغاته, وأفضل ما القارئ إليه مُحتاج:معرفة إعرابه, والوقوف على تصرف حركاته, وسواكنه ؛ ليكون بذلك سالماً من اللحن فيه, مستعيناً على أحكام اللفظ به, مُطلعاً على المعاني

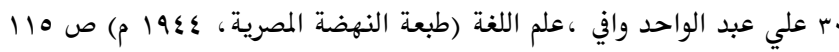

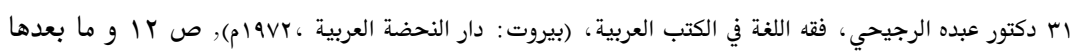

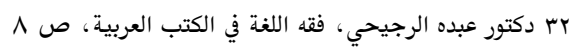

$$
\begin{aligned}
& \text { بس الدكتورعلي عبد الواحد وافي، فقه اللغة، طب، ص } 9 \text { و ما بعدها. }
\end{aligned}
$$

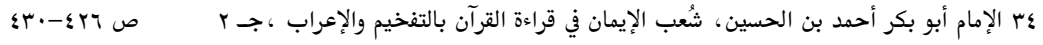

\section{'A Jami Jurnal Bahasa dan Sastra Arab}

Volume 08, No. 1, Juni 2019 ISSN: 2252-9926 (Print), ISSN: 2657-2206 (Online) 
16

التي قد تختلف باختلاف الحركات, متفهماً لما أراد الله به من عباده, إذ بمعرفة حقائق الإعراب تعرف أكثر المعاني, ويذجلي الإشكال, فتظهر الفوائد ويُفهم الخطاب, وتصح معرفة حقيقة المراد". هـ

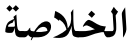

إن والإعراب في اصطلاح النحاة هو تغيير يلحق آخر الكلمة حقيقة أو حكماً بسبب اختلاف العوامل الداخلة عليها من عامل يقتضي الرفع إلى آخر يقتضي النصب إلى ثالث يقتضي الجر إلى رابع يقتضي الجزم. أما النحو فهو انتحاء سمت كلام العرب، في تصريفه من إعراب و غيره، كالتثنية و الجمع، و التحقير و التكسير و الإضافة، و النسب، و التركيب، و غير ذلك، ليلحق من ليس من أهل اللغة العربية بأهلها في الفصاحة، فينطق بها و إن لم يكن منهم، و إن شد بعضهم عنها رد به إليها

$$
\text { مراجع }
$$

ابن منظور، لسان العرب(، بيروت: دار صادر)

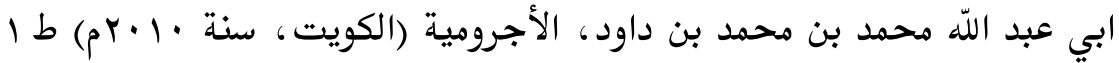

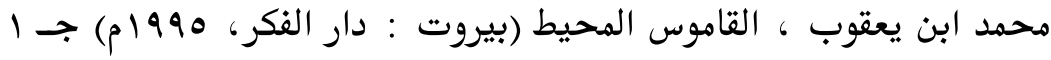

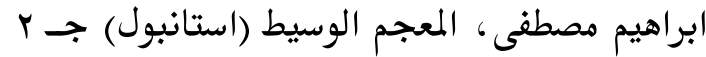

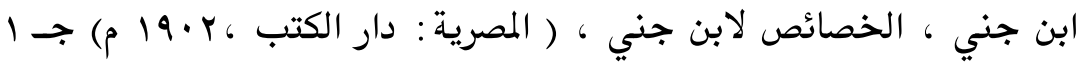

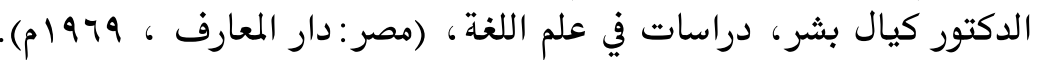

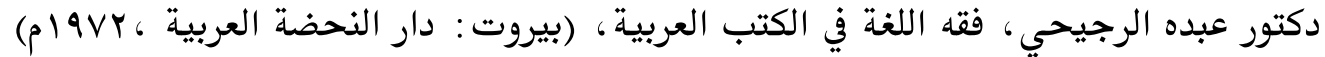

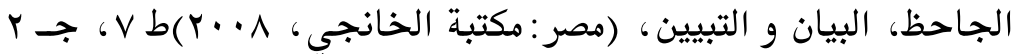

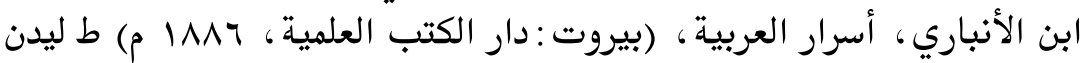

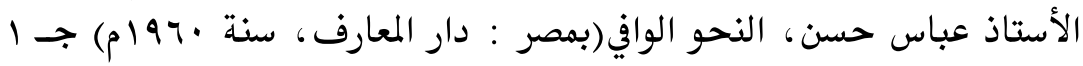

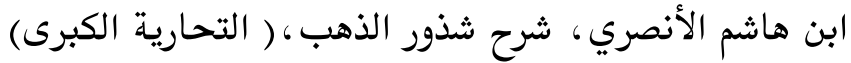

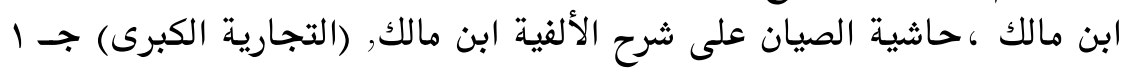

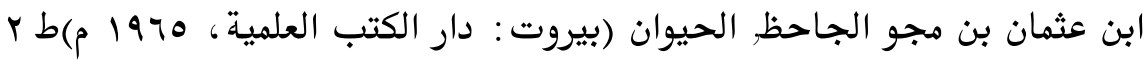

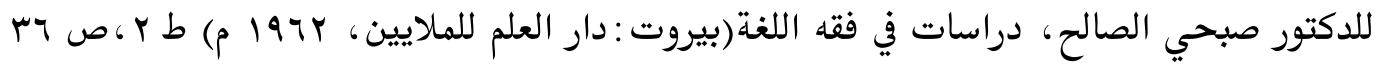

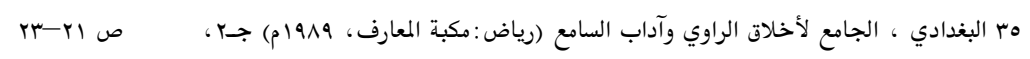

\section{'A Jami Jurnal Bahasa dan Sastra Arab}

Volume 08, No. 1, Juni 2019 ISSN: 2252-9926 (Print), ISSN: 2657-2206 (Online) 